\title{
Association of sella turcica bridging with palatal canine impaction in skeletal Class I and Class II
}

This article was published in the following Dove Press journal:

Clinical, Cosmetic and Investigational Dentistry

\author{
Laila Fawzi Baidas' \\ Huda Mohammad \\ Al-Kawari' \\ Zhara Al-Obaidan ${ }^{2}$ \\ Aqeelah Al-Marhoon ${ }^{2}$ \\ Sawsan Al-Shahrani ${ }^{2}$ \\ 'Department of Pediatric Dentistry \\ and Orthodontics, College of \\ Dentistry, King Saud University, \\ Riyadh, Saudi Arabia; ${ }^{2}$ College of \\ Dentistry, King Saud University, \\ Riyadh, Saudi Arabia
}

Purpose: Based on the evidence of the embryonic origin of the sella turcica and the teeth, this retrospective study evaluated the association between sella turcica bridging and palatal canine impaction in skeletal Class I and Class II orthodontic patients.

Methods: Sixty-two orthodontic patients with palatally impacted canines and 54 controls with erupted canines (aged 12-25 years) were classified into skeletal Class I and Class II (according to ANB angle and Wits analysis). The length, depth, and diameter of the sella turcica were measured, and the shape was described. The difference in linear dimensions between the study and control groups was calculated using two-way analysis of variance and Student's $t$-test. The interrelationship of the variables, subject groups, skeletal type, and age, with the linear dimensions of sella turcica, was tested using regression analyses. The association between sella turcica, bridging and palatally impacted canines was determined in skeletal type using a chi-square test.

Results: Highly significant differences were found in the length, diameter, and depth of the sella turcica between the study sample and the control ( $P<0.001, P=0.015, P<0.0001$, respectively). There was a highly significant frequency of bridging in cases with palatally impacted canines $(P<0.0001)$. An increasing incidence of bridging was found in subjects with palatally impacted canines and skeletal Class I $(P<0.0001)$ and Class II $(P=0.044)$ relationships. Regression analysis showed that the age was significantly related to a change in length $(P=0.025)$, diameter $(P<0.0001)$, and depth $(P<0.0001)$. The normal sella turcica morphology was present in most subjects $(56.4 \%)$, and no significant association was found in subjects with palatally impacted canines in terms of the shape of the sella turcica.

Conclusion: Sella turcica bridging is frequently seen in patients with impacted canines. The findings suggest that careful monitoring of canine eruption is required in patients diagnosed with sella turcica bridging at an early age.

Keywords: sella turcica bridging, sella turcica shape, skeletal type, palatally impacted canine

\section{Introduction}

The sella point constitutes a critical reference point in cephalometric analysis of dentofacial morphology. The shape of the sella turcica changes during growth by apposition at the tuberculum sellae, and resorption at the posterior boundary of the sella turcica occurs up to the age of 16-18 years. ${ }^{1,2}$ The sella turcica area is a critical point for the migration of neural crest cells to the frontonasal and maxillary area during embryologic development. Therefore, neural crest cells are involved in the formation and development of both the sella turcica and the teeth. ${ }^{3,4}$ The sella turcica is of vital importance in the field of orthodontics. The anterior wall of the sella turcica is
Correspondence: Laila Fawzi Baidas Department of Pediatric Dentistry and Orthodontics, College of Dentistry, King Saud University, P.O. Box 5967, Riyadh

I | 432, Saudi Arabia

Tel +966 I 18055724

Email lbaidas@ksu.edu.sa 
helpful in predicting patient growth, assessing the craniofacial morphology, and superimposing serial cephalograms. ${ }^{5}$ Additionally, orthodontists should be aware of and familiar with the morphologic variations of the sella turcica that help in understanding the underlying pathologies associated with it. One common morphologic variation of the sella turcica is sella turcica bridging. This irregular bridge formation of the sella turcica results from excessive ossification of the dura mater between the anterior and posterior clinoidal processes of the sphenoid bone. ${ }^{6-8}$ Hence, the sella turcica bridge can be considered as a developmental anomaly. In healthy individuals, the frequency of sella bridging ranges from $1.1 \%$ to $13 \%$. The anteroposterior diameter of the sella turcica varies from 5 to $16 \mathrm{~mm}$ and the vertical depth from 4 to $16 \mathrm{~mm} .^{9}$

According to the theories stating that HOX hedgehog gene mutations have a negative impact on the development of the midface, teeth, and part of the sella turcica, any alteration in the developmental level could result in sella turcica bridging that might also lead to dental anomalies. ${ }^{3}$ Kjaer $^{10}$ reported that abnormalities in the anterior wall of the sella turcica appear to be associated with defects in the frontonasal field. Furthermore, about half of the patients with cleft lip and palate $^{11}$ and almost half of the children with malocclusion have sella turcica abnormalities. ${ }^{12}$ All these findings confirm a genetic basis for sella turcica bridging.

Maxillary canine impaction is a dental anomaly found in $1 \%-2 \%$ of orthodontic patients, with a higher prevalence in female patients. ${ }^{13}$ This anomaly has multifactorial etiologic causes, and the guidance and genetic theories are most commonly cited to explain the etiology of maxillary canine impaction. ${ }^{14,15}$ According to the genetic theory, palatally impacted maxillary canines are likely to occur in combination with other genetic variations such as submerged deciduous molars, hypoplastic enamel, mandibular premolar aplasia, and diminutive maxillary lateral incisors. ${ }^{15,16}$ Therefore, early diagnosis and intervention for impacted canines can reduce the duration, expense, and complexity of treatment in the permanent dentition.

Many studies have linked sella turcica bridging to multiple hereditary developmental syndromes affecting the craniofacial region, and also many local dental anomalies such as tooth transposition, hypodontia, and missing mandibular second premolars. ${ }^{17,18}$ However, little research is available on the association between palatal canine impaction and sella turcica bridging, even though the dimensions of the sella turcica have a significant impact on bridging. ${ }^{19,20}$

There is increasing interest in the area of craniofacial dysmorphology, and in establishing the shape and size of the sella turcica to develop a standard for describing abnormal morphology in different skeletal patterns. Few studies have been done in this area, although the diameter of the sella turcica was found to be significantly greater in Class III subjects than in Class II subjects, ${ }^{21,22}$ and the depth of the sella turcica was reported to be smaller in Class II subjects than in Class I subjects. ${ }^{11}$

Accordingly, the objectives of this study were to test the association between sella turcica bridging with canine impaction, and to compare the linear dimensions and size of the sella turcica in subjects with palatally impacted vs. erupted canines in skeletal Class I and Class II subjects. The morphologic shape of the sella turcica in subjects with palatally impacted vs. erupted canines was also analyzed.

\section{Methods}

This retrospective study was conducted to determine the association between palatal canine impaction and sella turcica bridging in patients seeking orthodontic treatment at King Saud University College of Dentistry in Riyadh. Approval from the ethical committee of the College of Dentistry Research Center at King Saud University was obtained (registration No. IR0155). Patient consent was not required for this particular study by the ethics committee of the College of Dentistry Research Centre as all patients sign a consent form when they open a file at the College of Dentistry/King Saud University. The signed form states that all records, radiographs, photographs, and so on are the property of the hospital and may be used for teaching, clinical demonstration, or scientific publication.

Pretreatment records of subjects with impacted canines were collected from orthodontic patients visiting the dental screening clinics in the past 5 years from the College of Dentistry at King Saud University. Subjects with good quality standardized lateral cephalograms with a crystal-clear image of the sella turcica were included in the study, and individuals with significant illnesses or medical conditions were excluded. The impacted canines were diagnosed from dental panoramic radiographs, and the buccopalatal position was confirmed using the horizontal parallax technique (two periapical radiographs with a $45^{\circ}$ shift) or the vertical parallax technique (dental panoramic radiograph and anterior occlusal radiograph).

The cephalometric radiographs of 54 controlled patients (control group) and 62 patients with a palatally impacted canine (study group), aged 12-25 years, were used in this study. The radiographs were distributed according to skeletal type: Class I control group (29), Class II control group (25), Class I study group (35), and Class II study group (27). Classification of skeletal type into Class I and Class II 
was based on the ANB angle. The ANB angle revealed the severity of the skeletal jaw discrepancy, regardless of which jaw was malformed. The skeletal pattern was categorized as follows: angles of $\pm 2^{\circ}$ were classified as Class I and angles of $>4^{\circ}$ as Class II. ${ }^{23}$ To overcome the limitations of the ANB angle in describing the severity of the jaw discrepancy, Wits analysis was used (if AO-BO is $0-4 \mathrm{~mm}$, it is classified as a Class I skeletal base; if AO-BO is $>4 \mathrm{~mm}$, it is classified as Class II). The ANB angle and Wits analysis designate only the degree of the skeletal jaw discrepancy, regardless of which jaw is malformed. ${ }^{24}$

\section{Cephalometric tracing and measurements of the sella turcica}

The sella turcica was traced on each cephalometric radiograph on thin acetate paper under optimal illumination in a dark room. The sella turcica was drawn as a U-shaped structure from the tip of the tuberculum sella to the tip of the dorsum sellae. The configuration of the sella turcica included the sella turcica floor, the tuberculum sella, the dorsum sellae, and the anterior and posterior clinoid processes. The measurements were made to the nearest $0.1 \mathrm{~mm}$. The linear dimensions were measured using the methods of Silverman ${ }^{25}$ and Kisling. ${ }^{26}$ All reference lines used in the current study were located in the mid-sagittal plane (Figure 1).

1. Interclinoidal distance (length): Distance from the tip of the tuberculum sellae to that of the dorsum sellae.

2. Diameter of the sella turcica: Distance from the tip of the tuberculum sellae to the furthest point on the posterior inner wall of the fossa.

3. Depth of the sella turcica: Length of a line dropped perpendicularly from the line above to the deepest point on the sella floor.

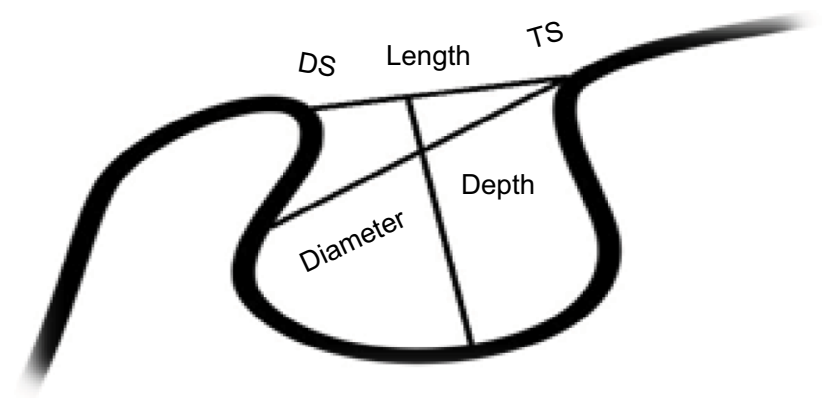

Figure I Normal sella turcica morphology and reference lines used for measuring sella size.

Abbreviations: TS, tuberculum sella; DS, dorsum sella; length of sella, diameter of sella, depth of sella.

\section{Bridging of the sella turcica}

The sella turcica length and diameter were compared using the standardized scoring scale developed by Leonardi et al. ${ }^{18}$ Based on the sella turcica dimensions, the bridging was classified into the following three types.

1. Type I: No bridging, where the length was either equal to or greater than three-fourths of the diameter.

2. Type II: Partial bridging, where the length was equal to or less than three-fourths of the diameter.

3. Type III: Complete calcification, where only the diaphragm sellae was visible on the radiograph.

\section{Shape of the sella turcica}

Six different morphologic appearances of the sella turcica devised by Axelsson et $\mathrm{al}^{9}$ were applied to determine the variations in the shape of the sella turcica (Figure 2).

\section{Reliability of measurements}

All the dimensions were measured by one investigator to reduce errors caused by intraoperator variability. Fifteen lateral cephalometric radiographs were chosen at random and traced, and then retraced after an interval of 3 weeks under identical conditions. The intraclass correlation coefficient, which is a function of these components, is a widely accepted index of measurement reliability.
A
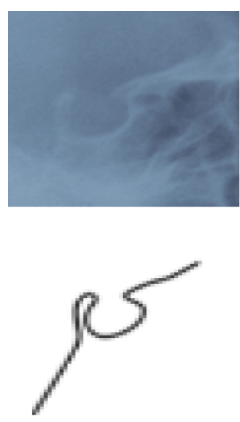

D

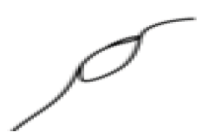

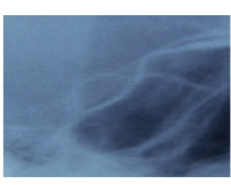

B
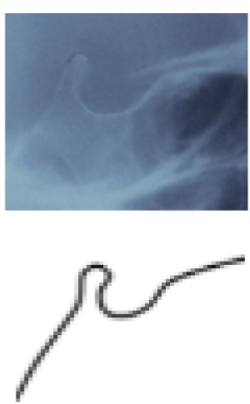

E

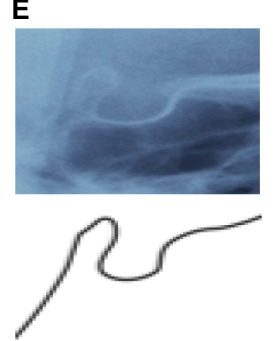

C
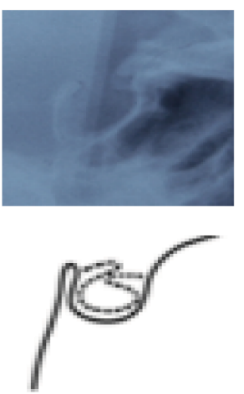

$\mathbf{F}$

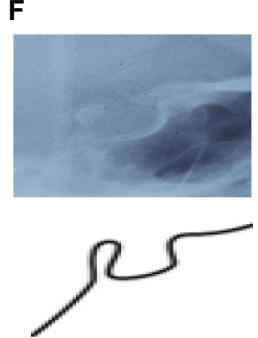

Figure 2 Different morphologic types of sella turcica: (A) normal sella turcica; (B) oblique anterior wall; (C) double contour of floor; (D) sella turcica bridge; (E) irregular dorsum sella; and $(\mathbf{F})$ pyramidal shape of dorsum sella. 


\section{Statistical analysis}

All statistical analyses were performed with SPSS software (Version 22, SPSS Inc., Chicago, IL, USA). The linear dimensions of the sella turcica between the control and study groups, and within the skeletal classifications and different age groups, were compared using two-way analysis of variance (ANOVA) followed by Student's $t$-test. Regression analyses were also used to test the interrelationship of the variables, subject groups, skeletal type, and age, with the linear dimensions of sella turcica. The association between sella turcica bridging in the study group and the control group, stratified by skeletal class, was evaluated using the chi-square test. Significance was calculated at a level of $<0.05$.

\section{Results}

Random errors were assessed using the intraclass correlation coefficient. The difference between the first and second measurements of the 15 radiographs was not significant and had high reliability $(0.86-1.00)$, which shows good reproducibility of the retraced radiographs.

Data on the skeletal classification distribution of the study group (with palatally impacted canines) and the control group are presented in Table 1. The sample consisted of 116 cephalometric radiographs selected from King Saud University orthodontic clinic: 54 in the control group (46.6\%) and 62 in the study group (53.4\%). About $55 \%$ of the samples were skeletal Class I and $45 \%$ were Class II.

\section{Size of the sella turcica}

The linear dimensions of the sella turcica are presented in Table 2. The mean length, diameter, and depth were 7.19,

Table I Frequency distribution of the sample according to skeletal classification

\begin{tabular}{llll}
\hline & Class I, N (\%) & Class II, N (\%) & Total, N (\%) \\
\hline Control & $29(45.3)$ & $25(48.1)$ & $54(46.6)$ \\
Study & $35(54.7)$ & $27(51.9)$ & $62(53.4)$ \\
\hline
\end{tabular}

Abbreviation: N, number.
10.59 , and $8.02 \mathrm{~mm}$ in the study group, and $9.18,11.35$, and $8.92 \mathrm{~mm}$ in the control group, respectively. The length, diameter, and depth of the sella turcica were significantly smaller in the study group than in the control group $(P<0.0001$, $P=0.015$, and $P<0.0001$, respectively). No significant differences were found in the linear dimensions of the sella turcica between skeletal Class I and Class II.

The average length, diameter, and depth of the sella turcica in the study and control samples, stratified by skeletal classification, are shown in Table 3. A two-way ANOVA test and an independent $t$-test were used to compare the linear dimensions of the sella turcica between the study and control groups with skeletal classification (Class I and Class II). No significant differences were found in linear dimensions of the sella turcica between skeletal Class I and Class II in either the study or the control group. However, highly significant differences were found in the length and depth of the sella turcica $(P<0.0001, P=0.005$, respectively) between the study and control groups in skeletal Class I subjects. Furthermore, the Class II study group had a significantly smaller length, diameter, and depth compared to the control group $(P<0.0001, P=0.015, P<0.0001$, respectively).

The regression analysis demonstrates the interrelationship between the variables, subject groups, skeletal type, and age, with the linear dimensions of the sella turcica (Table 4). The result of the regression model revealed that age was significantly related to length $(P=0.025)$, diameter $(P<0.0001)$, and depth $(P<0.0001)$ of sella turcica. However, the study group showed a highly significant decrease in length and depth of sella turcica by $1.818 \mathrm{~mm}(P<0.0001)$ and $0.704(P=0.002)$, respectively, compared to the control group when other variables are controlled. Additionally, in skeletal type Class II, the length and depth of sella turcica increased significantly by $0.832 \mathrm{~mm}(P=0.017)$ and $0.472 \mathrm{~mm}(P=0.038)$, respectively, compared to Class I, when other variables are fixed.

\section{Bridging of the sella turcica}

The occurrence of partial and complete bridging (Type II and Type III) in the study sample was $67.8 \%$ compared to

Table 2 Comparison of sella turcica linear dimensions $(\mathrm{mm})$ between the control and study samples, and between skeletal Class I and Class II

\begin{tabular}{|c|c|c|c|c|c|c|}
\hline & & Total, M (SD) & $P$-value* & & Total, M (SD) & $P$-value* \\
\hline \multirow[t]{2}{*}{ Length } & Control & $9.18( \pm 1.48)$ & $<0.0001$ & Class I & $7.78( \pm 2.33)$ & 0.057 \\
\hline & Study & $7.19( \pm 2.17)$ & & Class II & $8.53( \pm 1.76)$ & \\
\hline \multirow[t]{2}{*}{ Diameter } & Control & 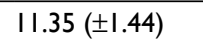 & 0.015 & Class I & $10.79( \pm 1.68)$ & 0.309 \\
\hline & Study & $10.59( \pm 1.81)$ & & Class II & $11.12( \pm 1.69)$ & \\
\hline \multirow[t]{2}{*}{ Depth } & Control & $8.92( \pm 1.55)$ & $<0.0001$ & Class I & $8.29( \pm 1.55)$ & 0.182 \\
\hline & Study & $8.02( \pm 1.36)$ & & Class II & $8.62( \pm 1.04)$ & \\
\hline
\end{tabular}

Note: $* P \leq 0.05$, two-way analysis of variance and independent $t$-test. 
Table 3 Comparison of sella turcica linear dimensions $(\mathrm{mm})$ between the control and study samples stratified by skeletal classification (Class I and Class II)

\begin{tabular}{|c|c|c|c|c|}
\hline & & Class I M (SD) & Class II M (SD) & $P$-value* \\
\hline \multirow[t]{2}{*}{ Length } & Control & $8.95( \pm 1.58)$ & $9.45( \pm 1.32)$ & 0.212 \\
\hline & Study & $6.81( \pm 2.42)$ & $7.68( \pm 1.70)$ & 0.119 \\
\hline$P$-value* & & $<0.0001$ & $<0.0001$ & \\
\hline \multirow[t]{2}{*}{ Diameter } & Control & II.03 ( \pm I.39) & II.72 ( $( \pm \mathrm{I} .42)$ & 0.078 \\
\hline & Study & $10.61( \pm 1.88)$ & $10.56( \pm \mathrm{I} .76)$ & 0.928 \\
\hline$P$-value* & & 0.318 & 0.013 & \\
\hline \multirow[t]{2}{*}{ Depth } & Control & $8.87( \pm 1.34)$ & $8.97( \pm 0.96)$ & 0.758 \\
\hline & Study & $7.80( \pm 1.55)$ & $8.29( \pm 1.01)$ & 0.154 \\
\hline$P$-value* & & 0.005 & 0.018 & \\
\hline
\end{tabular}

Note: $* P \leq 0.05$, two-way analysis of variance and independent $t$-test.

Table 4 Regression analysis for variables (subject groups, skeletal classification, and age) and linear dimension (length, diameter, and depth)

\begin{tabular}{|c|c|c|c|c|c|c|c|c|c|c|}
\hline \multirow{2}{*}{$\begin{array}{l}\text { Linear } \\
\text { dimensions }\end{array}$} & \multirow[t]{2}{*}{ Variables } & \multicolumn{2}{|c|}{ Pearson correlation } & \multicolumn{4}{|c|}{ Unstandardized coefficients } & \multicolumn{3}{|c|}{ Model summary } \\
\hline & & $r$ & *P-value & B & SE & $t$ & *P-value & $R^{2}$ & $\boldsymbol{F}$ & *P-value \\
\hline \multirow[t]{4}{*}{ Length } & (Constant) & & & 7.242 & 0.770 & 9.409 & $<0.0001$ & 0.282 & 14.662 & $<0.0001$ \\
\hline & Subject group & -0.471 & $<0.0001$ & -1.818 & 0.346 & -5.261 & $<0.0001$ & & & \\
\hline & Skeletal type & 0.177 & 0.028 & 0.832 & 0.345 & 2.414 & 0.017 & & & \\
\hline & Age & 0.238 & 0.005 & 0.084 & 0.037 & 2.269 & 0.025 & & & \\
\hline \multirow[t]{4}{*}{ Diameter } & (Constant) & & & 8.720 & 0.653 & 13.359 & $<0.0001$ & 0.183 & 8.374 & $<0.0001$ \\
\hline & Study group & -0.226 & 0.007 & -0.514 & 0.293 & -1.753 & 0.082 & & & \\
\hline & Skeletal type & 0.095 & 0.155 & 0.508 & 0.292 & 1.736 & 0.085 & & & \\
\hline & Age & 0.369 & $<0.0001$ & 0.130 & 0.032 & 4.125 & $<0.0001$ & & & \\
\hline \multirow[t]{4}{*}{ Depth } & (Constant) & & & 6.841 & 0.502 & 13.614 & $<0.000 \mathrm{I}$ & 0.242 & 11.919 & $<0.000 \mathrm{I}$ \\
\hline & Study group & -0.334 & $<0.0001$ & -0.704 & 0.226 & -3.122 & 0.002 & & & \\
\hline & Skeletal type & 0.125 & 0.091 & 0.472 & 0.225 & 2.098 & 0.038 & & & \\
\hline & Age & 0.375 & $<0.0001$ & 0.101 & 0.024 & 4.156 & $<0.0001$ & & & \\
\hline
\end{tabular}

Notes: $r$, Pearson's correlation; B, regression coefficient; $t$, independent $t$-test; $R^{2}$, coefficient determination, $F$, analysis of variance $F$-test; *P $\leq 0.05$. Subject groups; study group reference to control group, skeletal type; Class II reference to Class I.

Abbreviation: SE, standard error.

the control sample at $26 \%$. Chi-square tests confirmed that there was a significant association $(P<0.0001)$ between sella turcica bridging and the presence of palatally impacted canines (Table 5). Chi-square tests were used to compare the incidence of bridging between the study and control samples in both Class I and Class II relationships (Table 6). The frequency of bridging was found to be significantly higher in the study group than in the control group in both skeletal Class I and Class II subjects $(P<0.001, P=0.044)$.

\section{Shape of the sella turcica}

The morphology of the sella turcica appeared to be normal in $56.4 \%$ of subjects regardless of age or skeletal type (Table 7). Variation in the morphologic appearance was present in $43.6 \%$ of subjects. An irregular dorsum sella was found in $17.2 \%$, while a double contour of the floor, sella turcica bridging, an oblique anterior wall, and a pyramidal shape of the dorsum sella were present in $8.6 \%, 7.7 \%, 5.2 \%$, and $5.2 \%$,
Table 5 Association of sella bridging in the study sample compared to controls using chi-square test

\begin{tabular}{lllll}
\hline & $\begin{array}{l}\text { Control, } \\
\text { N (\%) }\end{array}$ & $\begin{array}{l}\text { Study, } \\
\text { N (\%) }\end{array}$ & $\begin{array}{l}\text { Total, } \\
\text { N (\%) }\end{array}$ & P-value* \\
\hline Type I & $40(74.07)$ & $20(32.3)$ & $60(51.7)$ & $<0.000$ I \\
Type II & I $3(24.07)$ & $38(61.3)$ & $51(43.96)$ & \\
Type III & I (I.9) & $4(6.5)$ & $5(4.3)$ & \\
\hline
\end{tabular}

Notes: Type I, no bridging; Type II, partial bridging; Type III, complete bridging. $* P \leq 0.05$, chi-square $=20.21, \mathrm{df}=1$.

respectively. Chi-square test confirmed no association in the shape of the sella turcica between the study and control groups.

\section{Discussion}

The structure of the sella turcica can be seen on lateral cephalometric radiographs, and it is routinely traced as a part of cephalometric analysis. The morphology of the sella turcica is important in establishing a cephalometric reference point. The sella turcica is used for evaluating not only craniofacial 
Table 6 Association of sella bridging in the study sample compared to controls stratified by skeletal classification (Class I and Class II) using chi-square test

\begin{tabular}{|c|c|c|c|c|c|}
\hline & & Control, N (\%) & Study, N (\%) & Total, N (\%) & $P$-value* \\
\hline \multirow[t]{3}{*}{ Class I } & Type I & $22(34.4)$ & $8(12.5)$ & 30 (46.9) & $<0.0001$ \\
\hline & Type II & $6(9.4)$ & $23(35.9)$ & $29(45.3)$ & \\
\hline & Type III & $\mathrm{I}(\mathrm{I} .6)$ & $4(6.2)$ & $5(7.8)$ & \\
\hline \multirow[t]{3}{*}{ Class II } & Type I & $18(34.6)$ & $12(23.1)$ & $30(57.7)$ & 0.044 \\
\hline & Type II & $7(13.5)$ & $15(28.8)$ & $22(33.3)$ & \\
\hline & Type III & $0(0)$ & $0(0)$ & $0(0)$ & \\
\hline
\end{tabular}

Notes: Type I, no bridging; Type II, partial bridging; Type III, complete bridging. $* P \leq 0.05$.

Table 7 Frequency distribution of sella turcica shape and distribution

\begin{tabular}{llll}
\hline Shape of sella turcica & $\begin{array}{l}\text { Control, } \\
\text { N (\%) }\end{array}$ & $\begin{array}{l}\text { Study, } \\
\text { N (\%) }\end{array}$ & $\begin{array}{l}\text { Total, } \\
\text { N (\%) }\end{array}$ \\
\hline Normal & $3 I(57.4)$ & $35(56.5)$ & $66(56.4)$ \\
Oblique anterior wall & I (I.9) & $5(8.1)$ & $6(5.2)$ \\
Double contour of the floor & $7(13)$ & $9(4.8)$ & $10(8.6)$ \\
Bridging & $2(3.7)$ & $7(11.3)$ & $9(7.7)$ \\
Irregular dorsum sella & $10(18.5)$ & $10(16.1)$ & $20(17.2)$ \\
Pyramidal shape of dorsum sella & $3(5.5)$ & $3(4.8)$ & $6(5.2)$ \\
\hline
\end{tabular}

morphology, but also growth changes and orthodontic treatment results. ${ }^{27}$ This retrospective study aimed to investigate the association of sella turcica bridging with palatally impacted canines in skeletal Class I and Class II orthodontic patients, and to correlate the size, and determine the shape of, the sella turcica in the same subjects. To our knowledge this type of study has not been previously undertaken in Saudi orthodontic patients.

\section{The size of the sella turcica}

The linear measurements (length, depth, and diameter) of the sella turcica in the present study differed from those of previous studies. ${ }^{9,21,28}$ Quakinine and Hardy ${ }^{28}$ studied 250 sphenoidal blocks obtained from cadavers of different ages. They found that the average diameter of the sella turcica was $12 \mathrm{~mm}$, the average length was $8 \mathrm{~mm}$, and the average depth was $6 \mathrm{~mm}$. The length and depth measurements were smaller than the average dimensions in our samples. Some authors reported that the height of the gland was $2 \mathrm{~mm}$ shorter than the actual depth, which infers that the gland does not fill the whole volume of the sella turcica, and this should be considered during measurements. Axelsson et $\mathrm{al}^{9}$ reported a similar result in a Norwegian sample (age 6-21years). The linear dimensions in our sample were on average smaller than those in the Norwegian subjects. A study undertaken by Alkofide ${ }^{21}$ in Saudi subjects reported linear dimensions that were on average $0.63-3.03 \mathrm{~mm}$ larger than our sample.
These differences in measurements could be attributed to the differences in ethnicity in Axelsson et al's study ${ }^{9}$ and to differences in sample size in Alkofide' ${ }^{21}$ study, taking into consideration that the studies compared subjects with impacted canines and subjects with normally erupted canines.

Many studies have compared the skeletal type of individuals with sella turcica size to determine if a relationship exists. Skeletal type and linear measurements of the sella turcica were assessed, and no differences were found in the length, depth, and diameter between skeletal Class I and Class II subjects. This finding was in agreement with other studies. ${ }^{21,29,30}$ In contrast, Prarthna et $\mathrm{al}^{11}$ found a significant difference between Class I and Class II subjects in the depth of the sella turcica, with the smaller depth occurring in Class II subjects.

According to our study, subjects with a palatally impacted canine had a significant decrease in the linear dimensions of the sella turcica when compared to the control. These findings conflict with the studies of Najim and Nakib ${ }^{19}$ and Ali et $\mathrm{al},{ }^{20}$ who found that the length of the sella turcica was smaller in subjects with impacted canines, whereas the depth and diameter were not significantly different between the study groups.

In the present study, we found that the parameters length, diameter, and depth increase with age, and correlation between the age and the linear measurements was found to be statistically significant. These findings coincide with the findings of Kumar and Govindraju ${ }^{31}$ who found that the size of sella turcica increased with age. Axelsson et $\mathrm{al}^{9}$ and Alkofide ${ }^{21}$ showed that the sella turcica was larger in older subjects, and that the tendency for size to increase with age was a result of an increase in the diameter and depth while the length remained constant. When the effect of age on sella turcica of subject with an impacted canine was studied, the length and, to a lesser extent, depth of the sella turcica were consistently smaller than the control group. It is in agreement with Najim and Nakib's study. ${ }^{19}$ Considering that the length of the sella turcica remains almost unchanged with age, children 
in whom the length of the sella turcica is small compared to the diameter and depth should be followed up because they may be at greater risk of bridging and the consequent dental anomalies.

Possible reasons for these differences in values between studies could be attributed to the different ethnicity of the study samples, or differences in the method of measurement.

\section{Bridging of the sella turcica}

Calcification of the diaphragma sellae, observed radiologically, has been described as "bridging" of the sella turcica. It is considered to be a normal variant in the absence of clinical signs or symptoms. ${ }^{32}$ While many pathologic processes can be associated with this calcification, it has been suggested that calcification of the diaphragma sellae can occur at an early stage of development, and then may ossify in early childhood. This ossification could stem from the complex embryology of the sphenoid bone. ${ }^{27,33}$ According to this theory, a sella turcica bridge should be considered a developmental anomaly. Furthermore, the area anterior to the sella turcica in the early embryonic period develops predominantly from neural crest cells, so any structural deviations in the anterior wall are thought to be associated with deviations in facial skeleton development. ${ }^{34}$

In the present study, the prevalence of sella turcica bridging was investigated in a group of patients with palatally impacted canines and compared with normal subjects. The results showed a high frequency of sella turcica bridging in subjects with impacted canines, as reported by other studies. Leonardi et $\mathrm{al}^{17}$ found an increased incidence of partial bridging of the sella turcica in patients with dental abnormalities $(58.8 \%)$ vs. a control group (33.7\%), and a frequency of $17.6 \%$ for complete bridging. Another study by Leonardi et $\mathrm{al}^{18}$ showed an increased frequency of partial and complete bridging in subjects with dental transposition. Our findings were consistent with those of Najim and Nakib ${ }^{19}$ who found that bridging occurred $70 \%$ more frequently in subjects with palatally impacted canines. Ali et $\mathrm{al}^{20}$ reported an $80.6 \%$ incidence of partial and complete bridging in subjects with palatally impacted canines; this was higher than the incidence found in our study. The difference in result could be a result of differences in sample size and sample population.

The increased frequency of complete and partial bridging of the sella turcica in subjects with palatal canine impaction provides a further indication of a genetic basis for this condition. Because bridging in this region can appear during early childhood, it may provide a predictor to the early diagnosis of some conditions or act as a diagnostic aid of susceptibility to palatal canine impaction or other dental abnormalities.
Certainly, the findings of this study showed that subjects with calcification in the region of the sella turcica are at potential risk of developing palatal canine impaction. Diagnosis of sella turcica bridging should be approached with care, because fusion between the anterior and posterior clinoid processes can be assumed from the radiographic superimposition of these structures when there is no actual bony fusion., ${ }^{9,27}$ In the present study, if bony fusion had occurred, it would be expected to affect both the study and control groups, which was not the case. Even though the majority of sella turcica bridges are detectable early in life, in some cases, calcification develops over time and might only be observed on lateral cephalometric radiographs taken at a later stage.

Thus, sella turcica bridging highlights the risk of future palatal canine impaction, especially in children with a history of canine impaction in their parents or siblings. The findings suggest that watchful monitoring is needed for canine eruption in patients diagnosed with sella turcica bridging.

\section{Shape of the sella turcica}

Different shapes of the sella turcica have been reported in the literature. ${ }^{35-38}$ Gordon and Bell ${ }^{35}$ classified the sella turcica into circular, oval, and flattened, or saucer shaped, and most subjects had either a circular or a oval-shaped sella turcica. Davidoff and Epstein ${ }^{39}$ introduced the term "J-shaped" sella, and Fournier and Denizet ${ }^{40}$ used "omega sella" as a descriptive term. Other classifications are based on the contours of the sella floor, the angles formed by the contours of the anterior and posterior clinoid processes and the tuberculum sellae, and the fusion of both clinoid processes as a sella turcica bridge. ${ }^{27}$ Axelsson et $\mathrm{al}^{9}$ categorized the shape of the sella turcica into six main types: normal sella turcica, oblique anterior wall, double-contoured sella, sella turcica bridge, irregularity (notching) in the posterior part of the sella, and pyramidal shape of the dorsum sellae (Figure 2). An alteration in the shape of the sella turcica can be deceptive because it may be present in "normal" subjects ${ }^{35}$ as well as in medically compromised subjects, such as those with craniofacial deviation and spina bifida. ${ }^{27}$

In the current study, $56.4 \%$ of subjects appeared to have a normal-shaped sella turcica, while $43.6 \%$ presented with different aberrations. The frequency of normal morphology of the sella turcica in the present study was slightly lower than the rates reported by other studies. Axelsson et $\mathrm{al}^{9}$ reported $68 \%$ as normal. Alkofide ${ }^{21}$ evaluated the shape and size of the sella turcica in patients with skeletal Class I, Class II, and Class III relationships, and found a normal morphology of the sella turcica in $67 \%$ of cases. The remaining $33 \%$ 
presented with variations of sella turcica morphology. In a study conducted by Mahmood et al, ${ }^{29}$ the normal morphology was seen in $\sim 66 \%$ of subjects, and variations were present in $34 \%$ of subjects.

Our study found no significant differences in the shape of the sella turcica related to age or skeletal type between subjects with impacted canines and subjects with erupted canines. No similar studies comparing these factors with sella turcica shape were found in the literature.

The clinical importance of the present study is that it may assist in the early detection of canine impaction. The timing of preventive treatment of impacted canines is of vital importance for successful treatment outcomes. Therefore, if canine impaction is detected early and interceptive measures are promptly undertaken, the ongoing dilemma associated with canine impaction could be avoided. Additionally, it could result in a reduction in the duration, expense, and effort of orthodontic treatment. The orthodontist should become familiar with the different shapes of the sella turcica area to help distinguish pathology from normal development patterns.

Although the research fulfilled its aims, there were some limitations that may have affected the validity of this study. First, because of time limitations, the research was conducted with relatively small groups. Second, the cephalometric tracing was done on two-dimensional lateral cephalometric radiographs that have significant anatomical superimposition and display the sagittal plan with no illustration of the transverse and frontal plans. Future studies should increase the sample size and include Class III subjects in a random selection to generalize the results for larger groups. Additionally, recent developments in computed tomography in the dental field have resulted in the ability to take scans of a specified area, avoiding unneeded exposure of the excluded structures. This would provide the added advantage of measurement accuracy in all three dimensions with no superimposition.

\section{Conclusion}

From this study, it can be concluded that

1. Subjects with palatally impacted canines had a sella turcica with a significantly smaller length, diameter, and depth.

2. The effects of age on the size of sella turcica were significantly related to diameter and depth.

3. The frequency of sella turcica bridging is higher in subjects with palatally impacted canines.

4. The chance of having partial or complete bridging in subjects with palatally impacted canines is three times higher than in those with erupted canines.
5. Approximately $56 \%$ of the investigated subjects had a normal sella turcica.

\section{Acknowledgments}

The authors would like to thank Prof. Asma Al-Jobair (Professor and Consultant, Orthodontics and Pediatric Dentistry Department) and Mr. Nassr Al-Maflehi (Biostatistician from King Saud University) for their appreciated efforts and help in the statistical analysis of the data. The authors also would like to thank Prof. Eman Alkofide (Professor and Consultant, Orthodontic and Pediatric Dentistry Department). Finally, they thank Helen Jeays, BDSc AE, from Edanz Group (www. edanzediting.com/ac) for editing a draft of this paper.

\section{Disclosure}

The authors report no conflicts of interest in this work.

\section{References}

1. Bjork A. Cranial base development. Am J Orthod. 1955;41:198-225.

2. Melsen B. The cranial base: the postnatal development of the cranial base studied historically on human autopsy material. Acta Odontol Scand. 1974;32:57-71.

3. Miletich I, Sharpe PT. Neural crest contribution to mammalian tooth formation. Birth Defects Res C Embryo Today. 2004;72(2):200-212.

4. Morotomi T, Kawano S, Toyono T, et al. In vitro differentiation of dental epithelial progenitor cells through epithelial-mesenchymal interactions. Arch Oral Biol. 2005;50(8):695-705.

5. Bishara SE, Athanasiou AE. Cephalometric methods for assessment of dentofacial changes. In: Athanasiou AE, editor. Orthodontic Cephalometry. London: Mosby-Wolfe; 1995:105-125.

6. Dubrul EL. Oral anatomy. In: Sicher H, Dubrul EL, editors. The Skull. New Delhi: AITBS Publishers \& Distributor; 1996:13.

7. DuBoulay G, Tricky S. The choice of radiological investigations in the management of tumors around the sella. Clin Radiol. 1967;18(4):349-365.

8. Skrzat J, Szewczyk R, Walocha J. The ossified interclinoid ligament. Folia Morphol. 2006:65(3):242-245.

9. Axelsson S, Storhaug K, Kjær I. Post-natal size and morphology of the sell turcica. Longitudinal cephalometric standards for Norwegians between 6 and 21 years of age. Eur J Orthod. 2004;26(6):597-604.

10. Kjaer I. Sella turcica morphology and the pituitary gland - a new contribution to craniofacial diagnosis based on histology and neuroradiology. Eur J Orthod. 2015;37(1)28-36.

11. Prarthna B, Saurabh S, Batra P, Dhillon M. Sella turcica morphology -a diagnostic marker for skeletal class II malocclusion. J Dent Specialties. 2015;3:22-28.

12. Kucia A, Jankowski T, Siewniak M, et al. Sella turcica anomalies on lateral cephalometric radiographs of Polish children. Dentomaxillofac Radiol. 2014;43(8):20140165.

13. Bishara SE. Impacted maxillary canines: a review. Am J Orthod Dentofacial Orthop. 1992;101(2):159-171.

14. Becker A, Smith P, Behar R. The incidence of anomalous maxillary lateral incisors in relation to palatally displaced cuspids. Angle Orthod. 1981;51(1):24-29.

15. Peck S, Peck L, Kataja M. The palatally displaced canine as a dental anomaly of genetic origin. Angle Orthod. 1994;64(4):249-256.

16. Baccetti T. A controlled study of associated dental anomalies. Angle Orthod. 1998:68(3):267-274.

17. Leonardi R, Barbato E, Vichi M, Caltabiano M. A sella turcica bridge in subjects with dental anomalies. J Orthod. 2006;28(6):580-585. 
18. Leonardi R, Farella M, Cobourne MT. An association between sella turcica bridging and dental transposition. Eur J Orthod. 2011;33(4):461-465.

19. Najim AA, Nakib LA. A cephalometric study of sella turcica size and morphology among young Iraqi normal population in comparison to patients with maxillary malposed canine. J Baghdad Coll Dent. 2011;23:53-58.

20. Ali B, Shaikh A, Fida M. Association between sella turcica bridging and palatal canine impaction. Am J Orthod Dentofacial Orthop. 2014;146(4):437-441.

21. Alkofide E. The shape and size of the sella turcica in skeletal Class I, Class II, and Class III Saudi subjects. Eur J Orthod. 2007;29(5):457-463.

22. Sathyanarayana PH, Kailasam V, Chitharanjan BA. The size and morphology of sella turcica in different skeletal pattern among South Indian population. A lateral cephalometric study. J Ind Orthod Soc. 2013;47:266-271.

23. Pancherz H, Sack B. A critical analysis of the SNA, SNB and ANB angles assessing orthodontic treatment. Fortschr Kieferorthop. 1994:51(5):309-317.

24. Jacobson A. The "Wits" appraisal of jaw disharmony. Am J Orthod. 1975;67(2):125-138.

25. Silverman FN. Roentgen standards for size of the pituitary fossa from infancy through adolescence. Am J Roentgenol Radium Ther Nucl Med. 1957;78(3):451-460.

26. Kisling E. Cranial Morphology in Down's Syndrome. A Comparative Roentgen Cephalometric Study in Adult Males [master's thesis]. Copenhagen: Munksgaard; 1966.

27. Becktor JA, Einersen S, Kjaer I. A sella turcica bridge in subjects with severe craniofacial deviations. Eur J Orthod. 2000:22(1):69-74.

28. Quakinine GE, Hardy J. Microsurgical anatomy of the pituitary gland and sellar region. 1. The pituitary gland. Am Surg. 1987;53(5):285-290.
29. Mahmood AS, Bashir U, Ilyas T. The shape and size of the sella turcica in skeletal class I, II \& III in patients presenting at Islamic International Dental Hospital Islamabad. Pak Oral Dent J. 2011;31:104-110.

30. Valizadeh S, Shahbeig S, Mohseni S, Azimi F, Bakhshandeh H. Correlation of shape and size of sella turcica with the type of facial skeletal class in an Iranian group. Iran J Radiol. 2015;12:e16059.

31. Kumar TS, Govindraju P. Relationship between the morphological variation of sella turcica with age and gender: a digital radiographic study. J of Ind Aca of Oral Med \& Radiol. 2017;29(30):164-169.

32. Kantor ML, Norton LA. Normal radiographic anatomy and common anomalies seen in cephalometric films. Am J Orthod Dentofacial Orthop. 1987;91(5):414-426.

33. Inoue T, Rhoton AL Jr, Theele D, Barry M. Surgical approaches to the cavernous sinus: a microsurgical study. Neurosurgery. 1990;26(6):903-932.

34. Kjær I, Keeling JW, Reintoft I, Nolting D, Fischer Hansen B. Pituitary gland and sella turcica in human trisomy 21 fetuses related to axial skeletal development. Am J Med Genet. 1998;80(5):494-500.

35. Gordon MB, Bell AL. A roentgenographic study of the sella turcica in 104 normal children. NY State J Med. 1922;22:54-59.

36. Andredaki M, Koumantanou A, Dorotheou D, Halazonetis DJ. A cephalometric morphometric study of the sella turcica. Eur J Orthod. 2007;29(5):449-456.

37. Teal JS. Radiology of the adult sella turcica. Bull Los Angel Neuro Soc. 1977; 42:111-174.

38. Tetradis S, Kantor ML. Prevalence of skeletal and dental anomalies and normal variants seen in cephalometric and other radiographs of orthodontic patients. Am J Orthod Dentofac Orthop. 1999;116(5):572-577.

39. Davidoff LM, Epstein BS. The Abnormal Pneumoencephalogram. Philadelphia, PA: Lea and Fibiger; 1950.

40. Fournier AM, Denizet D. Omega shaped sella turcica. Mars Med. 1965;102(6):503-509.
Clinical, Cosmetic and Investigational Dentistry

\section{Publish your work in this journal}

Clinical, Cosmetic and Investigational Dentistry is an international peer-reviewed, open access, online journal focusing on the latest clinical and experimental research in dentistry with specific emphasis on cosmetic interventions. Innovative developments in dental materials, techniques and devices that improve outcomes and patient satisfaction

\section{Dovepress}

and preference will be highlighted. The manuscript management system is completely online and includes a very quick and fair peerreview system, which is all easy to use. Visit http://www.dovepress. com/testimonials.php to read real quotes from published authors. 